\title{
Recurrent Endometrial Carcinoma
}

National Cancer Institute

\section{Source}

National Cancer Institute. Recurrent Endometrial Carcinoma. NCI Thesaurus. Code C150094.

The reemergence of endometrial carcinoma after a period of remission. 